\title{
Deprivation and unintentional injury hospitalization in Quebec children
}

\author{
Mathieu Gagné, MA (1); Denis Hamel, MSc (1)
}

\begin{abstract}
Injuries disproportionately affect children from deprived areas. This study examines the links between the material and social dimensions of deprivation and injury hospitalizations in children aged 14 years or under from 2000 to 2004. Hospitalization data are from the Quebec hospital administrative data system, whereas socio-economic characteristics of individuals were estimated based on the smallest geographic areas for which Canadian census data were disseminated. The Poisson regression model was used to calculate the relative risks of hospitalization for seven categories of unintentional injury. A total of 24540 injury hospitalizations were examined. Hospitalization in children is associated with both dimensions of deprivation. Injuries to pedestrians and motor vehicle occupants and injuries related to burns and poisonings are clearly associated with both dimensions of deprivation. These inequalities should be considered in the development of preventive measures.
\end{abstract}

Key words: Socio-economic factors, inequalities, children, hospitalizations,

Quebec, injuries, trauma, unintentional

\section{Introduction}

Unintentional injuries are the leading cause of death and the third most common cause of hospitalization in Quebec children aged 1 to 14 years. Although the majority of children recover from an injury quickly and completely, some are affected by temporary, or even permanent, disabilities that can significantly restrict their quality of life. ${ }^{1}$

It is generally accepted that some children, particularly those from deprived areas, are at greater risk of sustaining an injury than others. ${ }^{2}$ With respect to mortality, the association between socio-economic factors and risk of injury has been extensively measured and illustrated. ${ }^{3-8}$ Some claim that inequalities in mortality are increasing, ${ }^{9}$ while others claim that gaps have held constant despite the observed decline

Research on the links between non-fatal injuries and socio-economic factors has yielded mixed results. ${ }^{11}$ A number of studies carried out in Quebec in the early 1990s show links between the deprived situation of some populations in the Montreal area and risk of injury in pedestrians and cyclists aged 14 years or under., ${ }^{5,12-14,16}$ The relationship between socio-economic characteristics and the risk of childhood injury has also been observed elsewhere in Canada. ${ }^{4,17,18}$ Some have observed that unintentional injury hospitalizations among children increased significantly with deprivation, ${ }^{19-28}$ while others did not find any association between the two phenomena. ${ }^{29-31}$ in mortality rates. ${ }^{10}$
Cubbin and Smith (2002) have identified some reasons that may explain these fluctuating results. ${ }^{11}$ First, the analyses do not always account for the level of injury severity nor define this level using a threshold that reflects the use of health care services. In the case of hospitalizations, a number of extrinsic factors on injury severity influence the likelihood of hospitalization, including bed availability, distance between home and hospital, concerns about whether the injury was intentional or even patient prefences. ${ }^{11,33}$ These factors can affect case identification in different ways. There is a risk of obscuring or magnifying the relationship between the injuries and deprivation if the severity of injuries is considered solely from the standpoint of services use. Second, the injury mechanism (i.e. falls, pedestrians, poisoning, etc.) is not always examined in detail. ${ }^{17,18}$ Some authors have nevertheless demonstrated that the effect of socio-economic factors can go in opposite directions when each mechanism is studied independently. ${ }^{34}$ Last, Cubbin and Smith (2002) emphasize that there are many measures, sometimes inadequately defined, by which socio-economic status can be expressed, whereas the choice of indicator is generally not justified by the investigators. ${ }^{11}$

Finally, we emphasize that few studies have focused on the social dimension of deprivation, i.e. the effect of social cohesion or isolation on injury risk, although this dimension is equally identified as a health determinant..$^{55}$ Recently, a measure of social fragmentation introduced to explain the association between injuries

Author References

1 Institut national de santé publique du Québec

Correspondence: Mathieu Gagné, Institut national de santé publique du Québec, 945 Wolfe Avenue, $3^{\text {rd }}$ Floor, Sainte-Foy, QC G1V 5B3,

Tel.: 418-650-5115, ext. 5702, Fax: 418-643-5099, Email: mathieu.gagne@inspq.qc.ca 
and deprivation in Sweden yielded no significant findings, after adjustment, for economic deprivation. ${ }^{56}$

\section{Study objective}

This study examines the links between unintentional injuries and deprivation in Quebec children. More specifically, we intend to establish whether hospital morbidity due to unintentional injury is associated with the material and social dimensions of deprivation in children aged 14 years or under in Quebec. We will then verify whether this relationship varies with the most important circumstances surrounding the injury. Finally, we will attempt to note whether the association also applies to severe injuries to ensure that the observed associations are not the result of administrative variations or a different use of health care services.

\section{Methods}

\section{Data sources}

Data used for this study are drawn from the records of the Quebec hospital client information system, called MED-ÉCHO. All Quebec children aged 14 years or under were selected if they were admitted to hospitals providing general and specialty care from January 1, 2000, to December 31, 2004, for short-term physical care of unintentional injuries. Case identification was based on the external cause of trauma and coded according to the rules of the International Classification of Diseases, Ninth Revision (E800-E949). Hospitalizations due to medical or surgical complications (E870-E879), adverse effects from the therapeutic use of medications (E930-E949) and after effects of injury (E905-E909) were excluded (i.e. 2358 cases). In addition, readmissions and transfers were excluded to limit the effects of variations related to service use and obtain a more robust morbidity indicator. ${ }^{32}$ Based on these criteria, we identified 24540 unintentional trauma-related events resulting in the hospitalization of children 14 years or under in Quebec during the period in question.
TABLE 1

Classification of unintentional injuries and main categories of external causes

\begin{tabular}{ll} 
Unintentional injuries & E800-E949 \\
Motor vehicle occupants & E810-E819; .0, .1 and .9 \\
Bicyclists & E810-E819; .6 and E826.1 \\
Pedestrians & E810-E819; .7 \\
Poisonings & E850-E869 \\
Falls & E880-E888 \\
Fires and burns & E890-E899 and E924 \\
\hline
\end{tabular}

Our measure of severity is based on the definition of the eligibility criteria used by the Registre des traumatismes du Québec (RTQ) [Québec Trauma Registry], which gathers information on victims of severe injuries. To be identified as severe, cases had to meet one of the following criteria: hospitalization for three days or more, admission to the intensive care unit (ICU), or death during hospitalization. This definition of a severe case was met by $24.8 \%$ of the 24540 cases.

\section{The deprivation index}

The administrative health databases in Quebec do not contain socio-economic information. For this reason, we used the deprivation index developed by Pampalon and Raymond (2000), which estimates an individual's socio-economic status using an ecological approach, i.e. by attributing to each individual admitted to hospital the socio-economic level of his or her neighbourhood. The index reflects relative disadvantage in relation to total population, which is expressed through a material and a social dimension. The material dimension reflects available economic resources or poverty, whereas the social dimension expresses the level of social cohesion or isolation, i.e. the quality or fragility of the social network. ${ }^{35}$

The index is obtained through the application of principal component analysis of six indicators taken from Canada's 2001 census, chosen for their known association with health inequalities. ${ }^{36}$ The material dimension of the index primarily consists of the following indicators: the proportion of persons with no high school diploma, the employment to population ratio and the average personal income. The social dimension of the index primarily consists of the following indicators: the proportion of persons who are separated, divorced or widowed, the proportion of persons living alone and the proportion of single-parent families. For both dimensions, a value is calculated for each dissemination area (DA), which is defined as a small, relatively stable geographic unit composed of one or more adjacent dissemination blocks, with 400 to 700 inhabitants, for which all census data are disseminated. ${ }^{35}$ The values are then grouped into quintiles (i.e. groups of $20 \%$ ) to create the index, ranging from the most privileged (i.e. quintile 1) to the least privileged (i.e. quintile 5). ${ }^{36}$ The key point is that each DA can be linked to a postal code, which appears in all administrative health records in Quebec. This strategy can be used to estimate the level of deprivation of the individuals for whom information is collected in our hospitalization records.

\section{Analysis}

Relative risks (RRs) of unintentional injury hospitalization were calculated along with confidence intervals of $95 \%$ (CI) by Poisson regression modelling using the GENMOD procedure (i.e. SAS, version 9.1) for each material and social deprivation quintile. The RRs were adjusted for differences in age, sex and residence location ${ }^{\mathrm{i}}$ between quintiles, but also for the presence of the other dimension of the index. For each analysis, the RR is interpreted based on the reference category, i.e. the most

i Census Metropolitan Area (CMA) of Montreal, other CMAs, other census agglomerations, small towns and rural areas. 
privileged quintile, for which the RR is set at 1.00. The value associated with the other quintiles expresses the RR of hospitalization between the most privileged quintile and the other quintiles.

\section{Results}

From 2000 to 2004, the annual average number of unintentional injuries resulting in hospitalization in children aged 0 to 14 in Quebec was 4908 (Table 2). This amounts to an annual rate of 384 injury hospitalizations per 100000 children. This rate is substantially higher in boys than in girls (i.e. 480 per 100000 and 285 per 100 000, respectively). It peaks in children aged 0 to 4 years (i.e. 421 per 100 000), declines in children aged 5 to 9 years (i.e. 336 per 100 000) and then rises again in children aged 10 to 14 years (i.e. 403 per $100000)$.

An examination of hospitalizations from a socio-economic standpoint indicates that they appear to be strongly associated with the material dimension of the deprivation index, with the rate increasing from
357 hospitalizations per 100000 in children in the most privileged quintile (i.e. Q1) to 426 in those from deprived areas (i.e. Q5). The association with the social dimension of deprivation is less pronounced. Children in the most privileged category have a slightly lower hospitalization rate than children in the least privileged category (i.e. 367 vs. 401 per 100 000).

\section{Injury mechanisms and location}

There are varying degrees of differences in most injury mechanisms between socioeconomic groups, which are generally

TABLE 2

Annual average numbers and injury hospitalization rates by age, sex, area of residence and the two dimensions of the deprivation index in children aged 14 years or under, based on severity, for all of Quebec, 2000 to 2004

\begin{tabular}{|c|c|c|c|c|}
\hline & \multicolumn{4}{|c|}{ Injuries resulting in hospitalization } \\
\hline & \multicolumn{2}{|c|}{ All } & \multicolumn{2}{|c|}{ Severe } \\
\hline & Number & Rate $^{*}$ & Number & Rate $^{*}$ \\
\hline 0 to 4 years & 1561 & 420.6 & 365 & 98.2 \\
\hline 5 to 9 years & 1519 & 335.6 & 342 & 75.5 \\
\hline Boys & 3127 & 480.4 & 811 & 124.5 \\
\hline Girls & 1781 & 284.5 & 406 & 64.9 \\
\hline \multicolumn{5}{|l|}{ Area } \\
\hline Small towns and rural areas ( $<10000$ inhabitants) & 1304 & 446.0 & 368 & 121.3 \\
\hline \multicolumn{5}{|l|}{ Material deprivation } \\
\hline Q1-Privileged quintile & 841 & 356.6 & 182 & 78.8 \\
\hline Q2 & 907 & 356.0 & 213 & 85.6 \\
\hline Q3 & 975 & 380.7 & 230 & 90.6 \\
\hline Q4 & 1032 & 397.3 & 267 & 101.4 \\
\hline Q5-Deprived quintile & 1152 & 426.0 & 325 & 116.2 \\
\hline \multicolumn{5}{|l|}{ Social deprivation } \\
\hline Q1-Privileged quintile & 1092 & 366.9 & 254 & 83.8 \\
\hline Q2 & 1088 & 374.1 & 265 & 90.5 \\
\hline
\end{tabular}

Rate adjusted for the other dimension of the index, age, sex and area of residence

Sources: INSPQ, MED-ÉCHO hospitalization records, 2000 to 2004

MSSS, demographic outlook based on the 2001 census 
more pronounced for the material dimension of the index. The gradients are particularly obvious for pedestrians, motor vehicle occupants, bicyclists, poisonings and fire and burn injuries (Table 3). Transportation-related injury categories are all strongly associated with the material dimension of deprivation, i.e. children from the least privileged areas have significantly higher RRs than their peers from privileged areas (i.e. motor vehicle occupants: $\mathrm{RR}=$ 1.69; pedestrians: $\mathrm{RR}=3.62$; bicyclists: $\mathrm{RR}=1.31$ ). RRs for bicyclists are significantly higher when analyses focus exclusively on accidents involving motor vehicles, with children from materially deprived areas still at a disadvantage (i.e. data not shown; $R R=1.75$ ). With respect to the social dimension of the index, children in the most deprived quintile have higher risks of hospitalization due to injuries suffered as a motor vehicle occupant or pedestrian (i.e. $\mathrm{RR}=1.32$ and 2.36, respectively). This is also found for the categories of poisoning (i.e. material dimension: $\mathrm{RR}=1.68$; social dimension: $\mathrm{RR}=1.66$ ) and fires and burns (i.e. material dimension: $R R=2.05$; social dimension: $\mathrm{RR}=1.50)$.

In contrast, the falls category as a whole shows no marked difference based on socioeconomic level (i.e. material dimension: $\mathrm{RR}=1.01$; social dimension: $\mathrm{RR}=1.00$ ). Hospitalizations for falls account for more than half (i.e. $51.3 \%$ ) of all unintentional injury hospitalizations in the study populaion, with this category covering a wide variety of circumstances. A different picture emerges (Table 4) when the main circumstances surrounding falls are identified. Children from materially deprived areas have a higher RR than their peers in privileged areas for falls on stairs (i.e. $R R=1.36$ ), falls from the top of a building (i.e. $R R=2.39$ ) and, to a lesser extent, falls from one level to another (i.e. $R R=1.09$ ), including falls from a bed or chair (i.e. data not shown; $R R=2.30$ ). A similar trend is observed for the social dimension of the index only for falls from the top of a building (i.e. $R R=1.96$ ). Conversely, the
RR for falls on same level from slipping, tripping or stumbling is substantially lower in children from deprived areas.

Moreover, between the injury location and both dimensions of the index, there also exists an association that changes, depending on the characteristics of the location in question $^{\text {ii }}$ (Table 5). For example, children from deprived areas have a higher RR of home injuries than their peers in privileged areas (i.e. material dimension: $\mathrm{RR}=1.50$; social dimension: $R R=1.18$ ). Conversely, materially deprived children have a significantly lower RR of recreational or sportrelated injuries than children from privileged areas (i.e. $\mathrm{RR}=0.66$ ).

\section{Nature of main traumatic injury and severity of injuries sustained}

To ensure that the observed associations were not caused by administrative variations or a differential use of health care services, our analyses were considered from the standpoint of injury characteristics. First, we examined the nature of the main traumatic injury by isolating a group of similar mechanisms, i.e. transportation accidents involving a pedestrian, bicyclist or motor vehicle occupant (Table 6). With respect to the material dimension, the $R R$ of a skull fracture and intracranial injury appears to be significantly higher in children from deprived areas compared with children in privileged categories (i.e. material dimension: $\mathrm{RR}=1.67$; social dimension: $\mathrm{RR}=1.52$ ). A similar finding, but of greater severity, emerges for lower limb injuries (i.e. material dimension: $\mathrm{RR}=2.58$; social dimension: $R R=1.70$ ) in contrast to upper limb fractures. Next, we repeated each analysis carried out to this point by selecting cases of severe injury only (Tables 7 to 9). Overall, the examination of severe injuries indicates that the measured associations persist and are nearly always more pronounced for the material dimension than for the social dimension, for which there is no clear trend.

\section{Discussion}

The results of the study show clearly that in Quebec, children from deprived areas are at greater risk of injury hospitalization than children from privileged areas. Recent data have confirmed the relationship between socio-economic characteristics and risk of childhood injury for all of Quebec, as observed in the early 1990s for the Montreal region. ${ }^{5,12-14,16}$ Our results suggest that these socio-economic differences exist not only in injury categories related to road accidents, but also, to varying degrees, in other categories such as injuries related to fires and burns, poisonings and certain circumstances surrounding falls, including falls on stairs. Unintentional injury in Quebec children are generally influenced by the two dimensions of deprivation. Most studies have underscored the association between risk of injury and the material dimension of deprivation (i.e. level of education, unemployment, income, father's occupation, access to a vehicle, housing tenure, financial difficulties, etc.), ${ }^{5,13-18,20,22,28,34,37}$ whereas the social dimension was viewed only partially through the lens of single-parent families, usually used as an indicator of poverty. ${ }^{37,38}$ However, our results suggest that the two dimensions of deprivation are independently associated with risk of hospitalization following an injury and that their effects may be cumulative. These results lend greater insight to the observations made for the entire Quebec population from 1997 to $2000,{ }^{53}$ when no significant trend between economic deprivation and unintentional traumas had previously been observed. Similarly, our results contrast with those recently obtained in the Swedish context, where no significant correlation between social isolation and injuries persisted after adjustment for economic deprivation. ${ }^{56}$

In order to minimize the effects of extrinsic factors on the severity of injuries on the probability of hospitalization, a severity measure was used to limit the analysis of injuries associated with a higher probability of hospitalization. Thus, as Hippisley-Cox et al. (2002) had observed for the Trent 
TABLE 3

Average annual number, adjusted* hospitalization rate and $\mathrm{RR} \dagger$ for main categories of unintentional injuries by the two dimensions of the deprivation index in children 14 years or under, for all of Quebec, 2000 to 2004

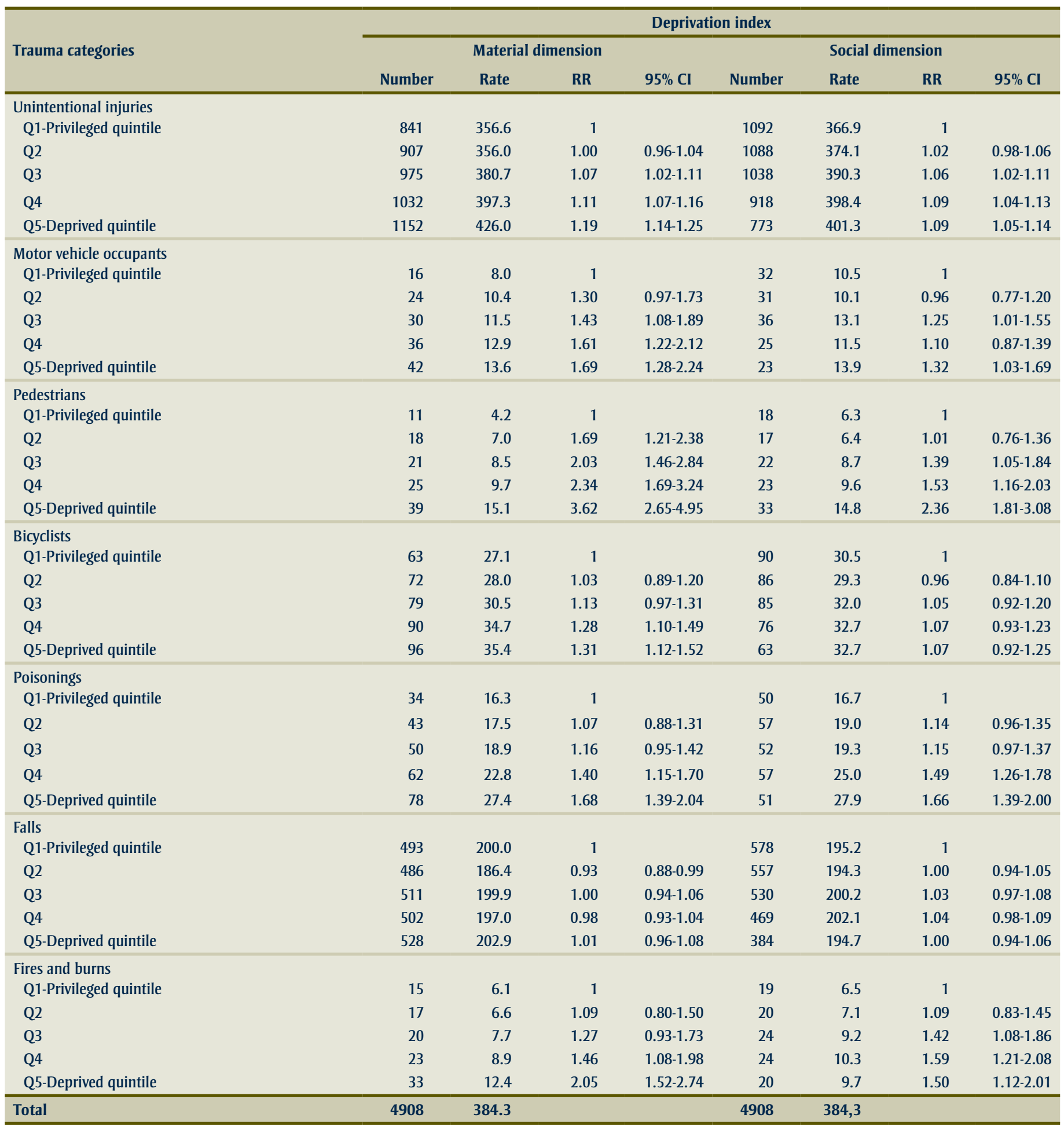

* Rate adjusted for the other dimension of the index, age, sex and area of residence

$\dagger$ Relative risk

Sources: MSSS, Med-Écho hospitalization records, 2000 to 2004

MSSS, demographic outlook 
TABLE 4

Average annual number, adjusted* hospitalization rate and $R \mathbf{R} \dagger$ for the main categories of falls by the two dimensions of the deprivation index in children 14 years or under, for all of Quebec, 2000 to 2004

\begin{tabular}{|c|c|c|c|c|c|c|c|c|}
\hline \multirow{3}{*}{ Circumstances of falls } & \multicolumn{8}{|c|}{ Deprivation Index } \\
\hline & \multicolumn{4}{|c|}{ Material dimension } & \multicolumn{4}{|c|}{ Social dimension } \\
\hline & Number & Rate & $\mathbf{R R}$ & $95 \% \mathrm{Cl}$ & Number & Rate & $\mathbf{R R}$ & $95 \% \mathrm{Cl}$ \\
\hline Q1-Privileged quintile & 29 & 11.9 & 1 & & 44 & 14.9 & 1 & \\
\hline Q2 & 33 & 13.0 & 1.09 & $0.87-1.37$ & 45 & 15.5 & 1.05 & $0.87-1.26$ \\
\hline Q5-Deprived quintile & 44 & 16.3 & 1.36 & $1.08-1.71$ & 26 & 13.3 & 0.90 & $0.72-1.12$ \\
\hline \multicolumn{9}{|c|}{ Falls from the top of building (E882) } \\
\hline Q1-Privileged quintile & 6 & 2.6 & 1 & & 8 & 2.8 & 1 & \\
\hline Q2 & 7 & 2.8 & 1.08 & $0.66-1.76$ & 11 & 4.0 & 1.43 & $0.96-2.14$ \\
\hline \multicolumn{9}{|c|}{ Other falls from one level to another (E884) } \\
\hline Q1-Privileged quintile & 172 & 68.7 & 1 & & 202 & 68.7 & 1 & \\
\hline Q2 & 178 & 68.1 & 0.99 & 0.90-1.09 & 197 & 69.3 & 1.01 & $0.92-1.10$ \\
\hline Q3 & 179 & 70.4 & 1.02 & $0.93-1.13$ & 186 & 70.8 & 1.03 & $0.94-1.13$ \\
\hline Q4 & 184 & 72.6 & 1.06 & $0.96-1.16$ & 171 & 73.3 & 1.07 & $0.97-1.17$ \\
\hline Q5-Deprived quintile & 192 & 74.6 & 1.09 & $0.98-1.20$ & 148 & 73.6 & 1.07 & $0.97-1.18$ \\
\hline \multicolumn{9}{|c|}{ Falls on same level from slipping, tripping or stumbling (E885) } \\
\hline Q1-Privileged quintile & 163 & 64.3 & 1 & & 162 & 54.6 & 1 & \\
\hline Q2 & 142 & 53.6 & 0.83 & $0.75-0.92$ & 153 & 53.4 & 0.98 & 0.89-1.08 \\
\hline \multicolumn{9}{|c|}{$\begin{array}{l}\text { Falls on same level from collision, pushing or shoving, } \\
\text { by or with another person (E886) }\end{array}$} \\
\hline Q2 & 36 & 13.7 & 0.89 & $0.73-1.10$ & 20 & 15.9 & 0.89 & $0.74-1.06$ \\
\hline Q3 & 47 & 18.4 & 1.20 & $0.98-1.46$ & 24 & 14.7 & 0.82 & $0.68-0.99$ \\
\hline Q4 & 37 & 14.8 & 0.96 & 0.78-1.19 & 24 & 15.7 & 0.87 & $0.72-1.06$ \\
\hline Q5-Deprived quintile & 39 & 15.5 & 1.01 & $0.81-1.25$ & 20 & 12.4 & 0.69 & $0.56-0.86$ \\
\hline \multicolumn{9}{|c|}{ Other falls (E881, E883, E887 and E888) } \\
\hline Q1-Privileged quintile & 85 & 36.7 & 1 & & 109 & 36.3 & 1 & \\
\hline Q2 & 89 & 35.0 & 0.95 & 0.83-1.09 & 106 & 36.2 & 1.00 & $0.88-1.12$ \\
\hline Q3 & 101 & 39.1 & 1.06 & $0.93-1.22$ & 111 & 41.6 & 1.15 & $1.02-1.29$ \\
\hline Q4 & 100 & 38.2 & 1.04 & $0.91-1.19$ & 94 & 41.2 & 1.13 & $1.00-1.29$ \\
\hline Q5-Deprived quintile & 121 & 44.1 & 1.20 & $1.05-1.38$ & 74 & 39.3 & 1.08 & $0.94-1.24$ \\
\hline
\end{tabular}

Rate adjusted for the other dimension of the index, age, sex and area of residence

$\dagger$ Relative risk

Sources: MSSS, Med-Écho hospitalization records, 2000 to 2004 MSSS, demographic outlook 
TABLE 5

Annual average number, adjusted ${ }^{*}$ hospitalization rate and $R \mathbf{R} \dagger$ for the place of injury by the two dimensions of the deprivation index in children aged 14 years or under, for all of Quebec, 2000 to 2004

\begin{tabular}{|c|c|c|c|c|c|c|c|c|}
\hline \multirow{3}{*}{ Injury location } & \multicolumn{8}{|c|}{ Deprivation Index } \\
\hline & \multicolumn{4}{|c|}{ Material dimension } & \multicolumn{4}{|c|}{ Social dimension } \\
\hline & Number & Rate & $\mathbf{R R}$ & $95 \% \mathrm{Cl}$ & Number & Rate & $\mathbf{R R}$ & $95 \% \mathrm{Cl}$ \\
\hline Q1-Privileged quintile & 308 & 128.0 & 1 & & 399 & 146.8 & 1 & \\
\hline Q2 & 344 & 138.3 & 1.08 & $0.91-1.29$ & 409 & 154.6 & 1.05 & $0.89-1.24$ \\
\hline Q5-Deprived quintile & 467 & 191.6 & 1.50 & $1.26-1.79$ & 345 & 173.9 & 1.18 & $1.00-1.41$ \\
\hline \multicolumn{9}{|l|}{ Recreational or sports area } \\
\hline Q1-Privileged quintile & 140 & 49.7 & 1 & & 138 & 41.6 & 1 & \\
\hline Q2 & 118 & 43.4 & 0.87 & $0.68-1.12$ & 127 & 41.1 & 0.99 & $0.78-1.25$ \\
\hline \multicolumn{9}{|l|}{ Public building } \\
\hline Q1-Privileged quintile & 56 & 21.9 & 1 & & 60 & 19.8 & 1 & \\
\hline Q2 & 45 & 16.8 & 0.77 & $0.62-0.95$ & 49 & 17.2 & 0.87 & $0.71-1.07$ \\
\hline Q3 & 48 & 18.5 & 0.85 & $0.69-1.05$ & 55 & 20.5 & 1.04 & $0.85-1.26$ \\
\hline Q4 & 46 & 18.1 & 0.83 & $0.67-1.03$ & 45 & 18.8 & 0.95 & $0.77-1.17$ \\
\hline Q5-Deprived quintile & 49 & 19.3 & 0.88 & $0.71-1.10$ & 36 & 18.2 & 0.92 & $0.73-1.15$ \\
\hline \multicolumn{9}{|l|}{ Other specified location } \\
\hline Q1-Privileged quintile & 21 & 9.5 & 1 & & 28 & 8.9 & 1 & \\
\hline Q2 & 25 & 10.2 & 1.08 & $0.80-1.45$ & 29 & 9.4 & 1.06 & $0.80-1.39$ \\
\hline Q3 & 243 & 93.2 & 1.03 & $0.92-1.16$ & 275 & 99.8 & 1.09 & $0.98-1.21$ \\
\hline Q4 & 258 & 97.8 & 1.09 & $0.97-1.22$ & 215 & 96.1 & 1.05 & $0.94-1.17$ \\
\hline Q5-Deprived quintile & 277 & 100.1 & 1.11 & $0.99-1.25$ & 163 & 93.0 & 1.02 & $0.90-1.14$ \\
\hline
\end{tabular}

* Rate adjusted for the other dimension of the index, age, sex and area of residence.

$\dagger$ Relative risk

Sources: MSSS, Med-Écho hospitalization records, 2000 to 2004 MSSS, demographic outlook 
TABLE 6

Average annual number, adjusted* hospitalization rate and $\mathrm{RR} \dagger$ for the main traumatic injury categories by the two dimensions of the deprivation index in children of 14 years or under, for all of Quebec, 2000 to 2004

\begin{tabular}{|c|c|c|c|c|c|c|c|c|}
\hline \multirow{3}{*}{ Traumatic injury categories } & \multicolumn{8}{|c|}{ Deprivation Index } \\
\hline & \multicolumn{4}{|c|}{ Material dimension } & \multicolumn{4}{|c|}{ Social dimension } \\
\hline & Number & Rate & $\mathbf{R R}$ & $95 \% \mathrm{Cl}$ & Number & Rate & $\mathbf{R R}$ & $95 \% \mathrm{Cl}$ \\
\hline \multicolumn{9}{|c|}{ Skull fractures and head traumas } \\
\hline Q1-Privileged quintile & 26 & 11.6 & 1 & & 41 & 13.9 & 1 & \\
\hline Q2 & 31 & 12.6 & 1.08 & $0.86-1.37$ & 39 & 13.3 & 0.96 & $0.79-1.17$ \\
\hline Q3 & 43 & 16.7 & 1.44 & $1.15-1.80$ & 47 & 17.7 & 1.27 & $1.06-1.54$ \\
\hline Q4 & 55 & 20.8 & 1.79 & $1.44-2.22$ & 43 & 18.4 & 1.33 & $1.09-1.61$ \\
\hline Q5-Deprived quintile & 54 & 19.4 & 1.67 & $1.34-2.09$ & 40 & 21.1 & 1.52 & $1.25-1.87$ \\
\hline \multicolumn{9}{|l|}{ Upper limb fractures } \\
\hline Q1-Privileged quintile & 28 & 11.0 & 1 & & 34 & 11.4 & 1 & \\
\hline Q2 & 30 & 11.2 & 1.01 & $0.80-1.28$ & 33 & 11.4 & 1.00 & $0.80-1.24$ \\
\hline Q3 & 24 & 9.5 & 0.86 & $0.67-1.10$ & 31 & 11.6 & 1.02 & $0.81-1.26$ \\
\hline Q4 & 33 & 13.0 & 1.18 & $0.93-1.49$ & 26 & 11.2 & 0.98 & $0.78-1.24$ \\
\hline Q5-Deprived quintile & 30 & 11.9 & 1.08 & $0.84-1.38$ & 22 & 10.8 & 0.95 & $0.74-1.22$ \\
\hline \multicolumn{9}{|l|}{ Lower limb fractures } \\
\hline Q1-Privileged quintile & 10 & 4.3 & 1 & & 21 & 7.0 & 1 & \\
\hline Q2 & 17 & 7.0 & 1.62 & $1.15-2.28$ & 16 & 5.5 & 0.79 & $0.59-1.05$ \\
\hline Q3 & 20 & 7.9 & 1.83 & $1.30-2.57$ & 18 & 7.1 & 1.02 & $0.77-1.35$ \\
\hline Q4 & 19 & 7.3 & 1.69 & $1.20-2.40$ & 19 & 8.2 & 1.18 & $0.89-1.56$ \\
\hline Q5-Deprived quintile & 31 & 11.2 & 2.58 & $1.85-3.60$ & 24 & 11.8 & 1.70 & $1.29-2.24$ \\
\hline
\end{tabular}

* Rate adjusted for the other dimension of the index, age, sex and area of residence

$\dagger$ Relative risk

Sources: MSSS, Med-Écho hospitalization records, 2000 to 2004 MSSS, demographic outlook 
TABLE 7

Average annual number, adjusted* hospitalization rate and $R \mathbf{R} \dagger$ for the main categories of severe unintentional injuries by the two dimensions of the deprivation index in children 14 years or under, for all of Quebec, 2000 to 2004

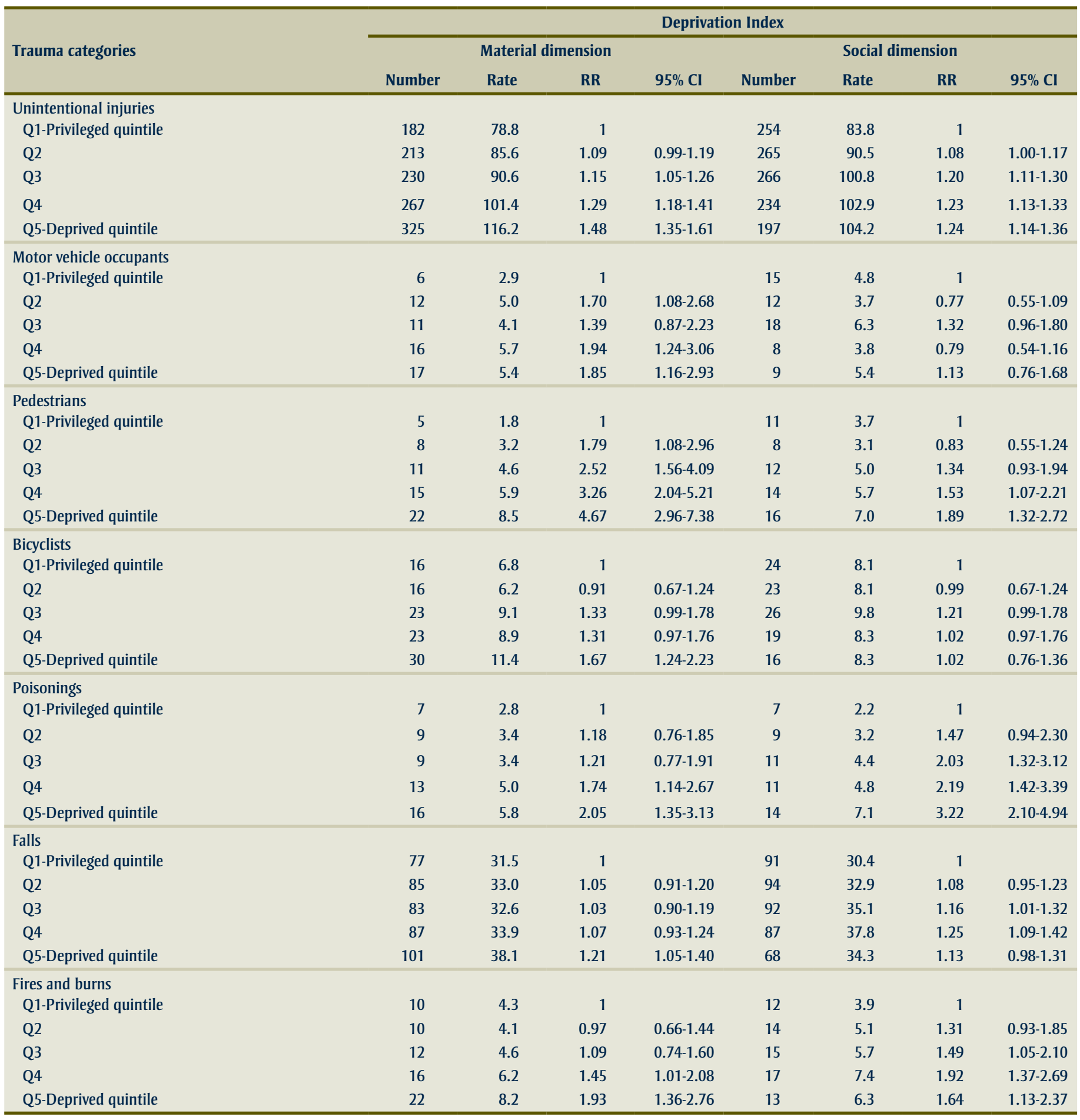

* Rate adjusted for the other dimension of the index, age, sex and area of residence

$\dagger$ Relative risk

Sources: MSSS, Med-Écho hospitalization records, 2000 to 2004

MSSS, demographic outlook 
TABLE 8

Average annual number, adjusted* hospitalization rate and $\mathbf{R R} \dagger$ for the main circumstances of falls resulting in severe injuries by the two dimensions of the deprivation index in children 14 years or under, for all of Quebec, 2000 to 2004

\begin{tabular}{|c|c|c|c|c|c|c|c|c|}
\hline \multirow{3}{*}{ Circumstances of falls } & \multicolumn{8}{|c|}{ Deprivation Index } \\
\hline & \multicolumn{4}{|c|}{ Material dimension } & \multicolumn{4}{|c|}{ Social dimension } \\
\hline & Number & Rate & $\mathbf{R R}$ & $95 \% \mathrm{Cl}$ & Number & Rate & $\mathbf{R R}$ & $95 \% \mathrm{Cl}$ \\
\hline Q1-Privileged quintile & 3 & 1.2 & 1 & & 5 & 1.8 & 1 & \\
\hline Q2 & 6 & 2.4 & 2.00 & $1.05-3.78$ & 7 & 2.4 & 1.34 & $0.81-2.21$ \\
\hline Q5-Deprived quintile & 8 & 3.0 & 2.51 & $1.32-4.79$ & 4 & 2.3 & 1.25 & $0.70-2.24$ \\
\hline \multicolumn{9}{|c|}{ Falls from or out of building or other structure (E882) } \\
\hline Q1-Privileged quintile & 2 & 0.7 & 1 & & 3 & 0.8 & 1 & \\
\hline Q2 & 2 & 0.8 & 1.04 & $0.40-2.72$ & 3 & 0.9 & 1.13 & $0.53-2.42$ \\
\hline \multicolumn{9}{|c|}{ Other falls from one level to another (E884) } \\
\hline Q1-Privileged quintile & 21 & 8.3 & 1 & & 26 & 8.6 & 1 & \\
\hline Q2 & 27 & 10.5 & 1.26 & $0.98-1.63$ & 28 & 9.8 & 1.14 & $0.90-1.45$ \\
\hline Q3 & 26 & 10.4 & 1.25 & $0.96-1.63$ & 29 & 11.1 & 1.29 & $1.02-1.64$ \\
\hline Q4 & 29 & 11.4 & 1.37 & $1.06-1.78$ & 26 & 11.4 & 1.32 & $1.03-1.69$ \\
\hline Q5-Deprived quintile & 32 & 12.0 & 1.44 & $1.10-1.87$ & 26 & 12.9 & 1.50 & 1.17-1.93 \\
\hline \multicolumn{9}{|c|}{ Falls on same level from tripping, slipping or stumbling (E885) } \\
\hline Q1-Privileged quintile & 31 & 12.5 & 1 & & 32 & 10.9 & 1 & \\
\hline Q2 & 32 & 11.9 & 0.95 & 0.76-1.19 & 30 & 10.4 & 0.96 & $0.77-1.20$ \\
\hline Q3 & 10 & 3.7 & 1.09 & $0.71-1.66$ & 15 & 2.8 & 0.94 & $0.60-1.45$ \\
\hline Q4 & 7 & 2.8 & 0.82 & $0.51-1.30$ & 17 & 3.3 & 1.11 & $0.72-1.71$ \\
\hline Q5-Deprived quintile & 7 & 2.9 & 0.84 & $0.52-1.36$ & 13 & 2.7 & 0.90 & $0.55-1.47$ \\
\hline \multicolumn{9}{|c|}{ Other falls (E881, E883, E887 and E888) } \\
\hline Q1-Privileged quintile & 12 & 5.2 & 1 & & 16 & 5.2 & 1 & \\
\hline Q2 & 11 & 4.6 & 0.89 & $0.61-1.28$ & 16 & 5.5 & 1.06 & $0.77-1.44$ \\
\hline Q3 & 15 & 5.9 & 1.15 & $0.81-1.63$ & 17 & 6.4 & 1.21 & $0.89-1.65$ \\
\hline Q4 & 15 & 5.7 & 1.11 & $0.78-1.59$ & 15 & 6.8 & 1.29 & $0.94-1.78$ \\
\hline Q5-Deprived quintile & 23 & 8.2 & 1.58 & $1.12-2.23$ & 12 & 6.4 & 1.22 & $0.86-1.73$ \\
\hline
\end{tabular}

* Rate adjusted for the other dimension of the index, age, sex and area of residence

$\dagger$ Relative risk

Sources: MSSS, Med-Écho hospitalization records, 2000 to 2004 MSSS, demographic outlook 
TABLE 9

Average annual number, adjusted ${ }^{*}$ hospitalization rate and $R \mathbf{R} \dagger$ for the incident location of severe injuries, by the two dimensions of the deprivation index in children 14 years or under, for all of Quebec, 2000 to 2004

\begin{tabular}{|c|c|c|c|c|c|c|c|c|}
\hline \multirow{3}{*}{ Incident location } & \multicolumn{8}{|c|}{ Deprivation Index } \\
\hline & \multicolumn{4}{|c|}{ Material dimension } & \multicolumn{4}{|c|}{ Social dimension } \\
\hline & Number & Rate & $\mathbf{R R}$ & $95 \% \mathrm{Cl}$ & Number & Rate & $\mathbf{R R}$ & $95 \% \mathrm{Cl}$ \\
\hline Q1-Privileged quintile & 80 & 32.5 & 1 & & 96 & 32.4 & 1 & \\
\hline Q2 & 91 & 36.5 & 1.12 & $0.92-1.38$ & 109 & 40.3 & 1.24 & $1.03-1.50$ \\
\hline Q5-Deprived quintile & 125 & 48.1 & 1.48 & $1.21-1.82$ & 94 & 47.0 & 1.45 & $1.19-1.77$ \\
\hline \multicolumn{9}{|l|}{ Recreational or sports area } \\
\hline Q1-Privileged quintile & 27 & 9.9 & 1 & & 24 & 7.2 & 1 & \\
\hline Q2 & 25 & 9.5 & 0.97 & $0.67-1.39$ & 25 & 8.5 & 1.18 & $0.82-1.69$ \\
\hline \multicolumn{9}{|l|}{ Public building } \\
\hline Q1-Privileged quintile & 6 & 2.7 & 1 & & 8 & 2.8 & 1 & \\
\hline Q2 & 8 & 3.3 & 1.22 & $0.75-1.97$ & 8 & 2.7 & 0.96 & $0.61-1.51$ \\
\hline Q3 & 8 & 3.0 & 1.12 & $0.68-1.85$ & 9 & 3.2 & 1.17 & $0.75-1.82$ \\
\hline Q4 & 7 & 2.7 & 1.01 & $0.60-1.69$ & 8 & 3.5 & 1.25 & $0.80-1.97$ \\
\hline Q5-Deprived quintile & 8 & 2.8 & 1.03 & $0.61-1.74$ & 4 & 2.4 & 0.87 & $0.50-1.49$ \\
\hline \multicolumn{9}{|l|}{ Other specified location } \\
\hline Q1-Privileged quintile & 6 & 5.5 & 1 & & 8 & 3.9 & 1 & \\
\hline Q2 & 6 & 4.1 & 0.74 & $0.52-1.07$ & 11 & 4.5 & 1.17 & $0.84-1.62$ \\
\hline Q3 & 45 & 17.2 & 1.32 & $1.04-1.67$ & 54 & 20.0 & 1.41 & $1.15-1.73$ \\
\hline Q4 & 49 & 18.1 & 1.38 & $1.09-1.76$ & 38 & 17.2 & 1.21 & $0.98-1.51$ \\
\hline Q5-Deprived quintile & 63 & 20.7 & 1.58 & $1.24-2.01$ & 32 & 19.8 & 1.39 & $1.11-1.76$ \\
\hline
\end{tabular}

Rate adjusted for the other dimension of the index, age, sex and area of residence

$\dagger$ Relative risk

Sources: MSSS, Med-Écho hospitalization records, 2000 to 2004 MSSS, demographic outlook 
Region in the United Kingdom, associations persist upon examination of severe injuries even when injury mechanisms are studied independently. ${ }^{22}$ These findings, however, should be interpreted with caution, given the weak frequency upon which they are based. Moreover, the nature of the injuries sustained also appears to be associated with socio-economic disparities, skull fractures and traumas, and lower limb fractures occurring proportionally more often in children from deprived areas. These results are particularly significant, as they suggest that severe injury hospitalizations (i.e. skull fractures, intracranial injuries and lower limb fractures) are strongly associated with deprivation, whereas no association was found for somewhat less severe injuries (i.e. upper limb fractures) involving mechanisms known for their strong association with deprivation.

Whereas there are numerous associations between socio-economic characteristics and injury risk, how the causal link operates has not been clearly demonstrated. These associations could be attributable to multiple individual or environmental factors that directly or indirectly influence injury risk. ${ }^{41}$ A significant amount of the research conducted to date has concentrated on individual characteristics to explain the differences observed in the risk of young children sustaining an injury, including family characteristics such as early motherhood, ${ }^{26,42,43}$ single-parent families, ${ }^{3,38}$ or even the number of children in the household. ${ }^{14}$ Other authors have also pointed to the effect of parents with a low level of education. ${ }^{8,14}$ These factors, usually associated with poverty, would particularly influence the immediate level and nature of child supervision. Pless et al. (1989) emphasize that the links between child behavioural characteristics and injury risk in pedestrians and bicyclists were more tenuous than the links between family or neighbourhood characteristics and such injuries. It is obvious here that children from socially isolated environments are at greater risk of hospitalization following an injury, perhaps in part, because the quality of the social network affects the parent's mental health, ${ }^{52}$ a risk factor in child injuries. Still another possibility is that, in a single-parent situation, the parent assumes several responsibilities alone, which may limit the nature of supervision provided to the child. ${ }^{54}$

Other approaches have shed new light on the contribution of environmental factors, including the home environment, which can directly or indirectly affect children. With respect to road injuries, for example, a number of authors have suggested that children from deprived areas live in neighbourhoods that have particular characteristics. The arrangement of roads and buildings can influence risk exposure due to the volume and speed of motor vehicle traffic, on-street parking and the lack of safe play areas, causing children to use the roads for "recreation". ${ }^{24,41,44}$ In addition, children from deprived areas are more likely to walk to school compared with their peers in privileged areas, and be accompanied by an adult less often. ${ }^{45,46}$ It is difficult to separate the variations attributable to individual or environmental characteristics. However, recent observations through multilevel analysis have demonstrated an effect on injury risk independent of home environment-regardless of the effects of individuals' socio-economic characteristics. $^{26,37,47}$

With regard to the other mechanisms, other home environment characteristics have been identified as influencing the risk of injury. Housing conditions can affect injury risk $^{48}$ in that poor housing is less likely to meet existing safety standards, especially for electrical and heating systems and stairs. Overcrowded, dilapidated housing generally tends to be occupied by materially deprived families. Moreover, it appears that safe practices and the ownership of safe equipment is less common in families from deprived areas than in those from privileged areas. ${ }^{49}$ From this viewpoint, studies carried out in the United Kingdom suggest that hospitalizations for poisoning, particularly from the use of benzodiazepine, antidepressants, and cough and cold medications, were significantly higher in children from deprived areas. ${ }^{20}$ The authors explain that the association is due to a greater exposure to these substances in deprived areas, owing to the quantity and availability of potentially toxic products, the locations where they are stored and the containers used to store them. Finally, poverty plays an important role in the lack of ownership of safe equipment and the adoption of safe practices. ${ }^{49}$ In other words, the observed differences could be bridged more easily by eliminating economic barriers and distributing safe, affordable or free equipment, for example.

\section{Limitations of this study}

The data forming the basis of our study include all hospitalizations in Quebec. However, this knowledge base does not include a known, standardized indicator that would establish a severity level of injuries sustained. Consequently, we used an approximate measure based on the eligibility criteria used by the RTQ database. This could give rise to criticism that the measure's capacity to eliminate administrative variations has not been proven. Furthermore, the MED-ECHO database contains no socio-economic information. To circumvent this problem, we used the deprivation index developed by Pampalon and Raymond (2000). However, an ecological index opens the door to similar errors, i.e. the socio-economic characteristics measured for a DA do not correspond to those of the families within the area. Given the number of studies in which this relationship has been observed through individual and ecological data, we believe that this limitation is of little relevance in this case.

\section{Conclusion}

The results of this study suggest that deprivation in Quebec children is associated with hospitalization risks for a great range of unintentional injuries for both dimensions of deprivation. In addition, examination of the injuries sustained tells us that the associations noted are not the result of differential health care services use or even administrative variations, given severe injuries are equally related to deprivation. These findings should be taken into account when developing preventive strategies.

The use of socio-demographic characteristics to identify children at risk of injury in order to develop targeted interventions has recently come under criticism. These 
critics have instead recommended using a population-based approach adapted to each population sub-group, ${ }^{43}$ because restricting preventive interventions to children from deprived areas means a significant number of injury victims would not benefit from the interventions. On the other hand, it appears that a physical modification of the environment is more successful in preventing injuries than most educational programs. ${ }^{50}$ From this perspective, measures aimed at modifying infrastructure to reduce traffic, while taking into account socioeconomic inequalities related to injuries in young pedestrians, have produced positive results in injury rates, in absolute terms, and in reducing relative inequalities. ${ }^{51}$

\section{Acknowledgements:}

The authors wish to thank Yvonne Robitaille, of the National Public Health Institute of Quebec, for her sound advice and thoughtful suggestions. We would also like to thank Robert Pampalon, also of the National Public Health Institute of Quebec, for his recommendations on the use of the deprivation index.

\section{References}

1. Polinder S, Meerding WJ, Toet $\mathrm{H}$ et al. Prevalence and prognostic factors of disability after childhood injury. Pediatrics. 2005;116: 810-17.

2. Dowswell T, Towner E. Social deprivation and the prevention of unintentional injury in childhood: a systematic review. Health Educ Res. 2002;17:221-37.

3. Blakely T, Atkinson J, Kiro C, et al. Child mortality, socioeconomic position, and oneparent families: independent associations and variation by age and cause of death. Int J Epidemiol. 2003;32:410-18.

4. Brownell M, Friesen D, Mayer T. Childhood injury rates in Manitoba: socioeconomic influences. Can J Public Health. 2002; Suppl 2:93:S50-S56.
5. Dougherty G, Pless IB, Wilkins R. Social class and the occurrence of traffic injuries and deaths in urban children. Can J Public Health. 1990;81:204-9.

6. Edwards P, Roberts I, Green J et al. Deaths from injury in children and employment status in family: analysis of trends in class specific death rates. Clinical research edition. BMJ. 2006;333:119.

7. LaflammeL, DiderichsenF. Social differences in traffic injury risks in childhood and youth-a literature review and a research agenda. Inj Prev. 2000;6:293-98.

8. Scholer SJ, Hickson GB, Ray WA. Sociodemographic factors identify US infants at high risk of injury mortality. Pediatrics. 1999;103:1183-188.

9. Roberts I, Power C. Does the decline in child injury mortality vary by social class? A comparison of class specific mortality in 1981 and 1991. BMJ. 1996;313:784-86.

10. Birken CS, Parkin PC, To T, et al. Trends in rates of death from unintentional injury among Canadian children in urban areas: influence of socioeconomic status. CMAJ. 2006;175:867.

11. Cubbin C, Smith GS. Socioeconomic inequalities in injury: critical issues in design and analysis. Annu Rev Public Health. 2002;23:349-75.

12. Joly MF, Foggin PM, Zvagulis I, et al. Bicycle accidents among children in the urban environment. Can J Public Health. 1989;80:351-54.

13. Joly MF, Foggin PM, Pless IB. Geographical and socio-ecological variations of traffic accidents among children. Soc Sci Med. 1991;33:765-69.

14. Pless IB, Verreault R, Tenina S. A casecontrol study of pedestrian and bicyclist injuries in childhood. Am J Public Health. 1989;79:995-98.

15. Pless IB, Peckham CS, Power C. Predicting traffic injuries in childhood: a cohort analysis. J Pediatr. 1989;115:932-38.
16. Pless IB, Verreault R, Arsenault L, et al. The epidemiology of road accidents in childhood. Am J Public Health. 1987;77:358-60.

17. Faelker T, Pickett W, Brison RJ. Socioeconomic differences in childhood injury: a population based epidemiologic study in Ontario, Canada. Inj Prev. 2000;6:203-8.

18. Gilbride SJ, Wild C, Wilson DR, et al. Socioeconomic status and types of childhood injury in Alberta: a population based study. BMC Pediatr. 2006;6:30.

19. Durkin MS, Davidson LL, Kuhn L, et al. Low-income neighbourhoods and the risk of severe pediatric injury: a smallarea analysis in northern Manhattan. Am J Public Health. 1994;84:587-92.

20. Groom L, Kendrick D, Coupland C et al. Inequalities in hospital admission rates for unintentional poisoning in young children. Inj Prev. 2006;12:166-70.

21. Hasselberg M, Laflamme L, Weitoft GR. Socioeconomic differences in road traffic injuries during childhood and youth: a closer look at different kinds of road users. J Epidemiol Community Health. 2001;55: 858-62.

22. Hippisley-Cox J, Groom L, Kendrick D et al. Cross sectional survey of socioeconomic variations in severity and mechanism of childhood injuries in Trent 1992-7. Clinical research edition. BMJ. 2002;324:1132.

23. Laing GJ, Logan S. Patterns of unintentional injury in childhood and their relation to socio-economic factors. Public Health. 1999;113:291-94

24. Mueller BA, Rivara FP, Lii SM, et al. Environmental factors and the risk for childhood pedestrian-motor vehicle collision occurrence. Am J Epidemiol. 1990; 132:550-60.

25. Pomerantz WJ, Dowd MD, Buncher CR. Relationship between socioeconomic factors and severe childhood injuries. J Urban Health. 2001;78:141-51. 
26. Reading R, Langford IH, Haynes R, et al. Accidents to preschool children: comparing family and neighbourhood risk factors. Soc Sci Med. 1999;48:321-30.

27. Rivara FP, Barber M. Demographic analysis of childhood pedestrian injuries. Pediatrics. 1985;76:375-381.

28. Silversides JA, Gibson A, Glasgow JF, et al. Social deprivation and childhood injuries in North and West Belfast. Ulster Med J. 2005;74:22-28.

29. Kelly S, Miles-Doan R. Social inequality and injury: do morbidity patterns differ from mortality? Soc Sci Med. 1997;44:63-70.

30. Lyons RA, Lo SV, Heaven M, et al. Injury surveillance in children-usefulness of a centralised database of accident and emergency attendances. Inj Prev. 1995; 1:173-76.

31. Lyons RA, Delahunty AM, Heaven M, et al. Incidence of childhood fractures in affluent and deprived areas: population based study. BMJ (Clinical research ed). 2000;320:149.

32. Robitaille Y, Gratton J. Les chutes chez les adultes âgés : vers une surveillance plus fine des données d'hospitalisation. Québec: Institut national de santé publique du Québec, 2005. 19 p.

33. Lyons RA, Brophy S, Pockett R, et al. Purpose, development and use of injury indicators. Int $\mathrm{J}$ Inj Contr Saf Promot. 2005;12:207-11.

34. Reimers A, Laflamme L. Neighbourhood social and socio-economic composition and injury risks. Acta Paediatr. 2005;94:1488-494.

35. Pampalon R, Raymond G. Indice de défavorisation matérielle et sociale : son application au secteur de la santé et du bien-être. Santé, société et solidarité 2003; 1:191-208

36. Pampalon R, Raymond G. A deprivation index for health and welfare planning in Quebec. Chronic Dis Can. 2000;21:104-13.
37. Kendrick D, Mulvaney C, Burton P, et al. Relationships between child, family and neighbourhood characteristics and childhood injury: a cohort study. Soc Sci Med. 2005;61:1905-915.

38. Roberts I, Pless B. Social policy as a cause of childhood accidents: the children of lone mothers. BMJ. 1995;311:925-28.

39. Alwash R, McCarthy M. Measuring severity of injuries to children from home accidents. Arch Dis Child. 1988;63:635-38.

40. Walsh SS, Jarvis SN, Towner EM, et al. Annual incidence of unintentional injury among 54,000 children. Inj Prev. 1996; 2:16-20.

41. Towner E, Dowswell T, Errington G, et al. Injuries in children aged 0-14 years and inequalities. Newcastle: Health Development Agency, Community Child Health, 2005.

42. Braun PA, Beaty BL, DiGuiseppi C, et al. Recurrent early childhood injuries among deprived children in primary care settings. Inj Prev. 2005;11:251-55.

43. Kendrick D, Marsh P. How useful are sociodemographic characteristics in identifying children at risk of unintentional injury? Public Health. 2001;115:103-7.

44. Roberts I, Norton R, Jackson R, et al. Effect of environmental factors on risk of injury of child pedestrians by motor vehicles: a casecontrol study. BMJ. 1995;310:91-94.

45. Towner EM, Jarvis SN, Walsh SS, et al. Measuring exposure to injury risk in school children aged 11-14. BMJ. 1994; 308:449-52.

46. Roberts I, Norton R. Auckland children's exposure to risk as pedestrians. $\mathrm{N} \mathrm{Z} \mathrm{Med} \mathrm{J.}$ 1994;107:331-33.

47. Haynes R, Reading R, Gale S. Household and neighbourhood risks for injury to 514 year old children. Soc Sci Med. 2003; 57:625-636.
48. Shenassa ED, Stubbendick A, Brown MJ Social disparities in housing and related pediatric injury: a multilevel study. Am J Public Health. 2004;94:633-39.

49. Hapgood R, Kendrick D, Marsh P. How well do socio-demographic characteristics explain variation in childhood safety practices? J Public Health Med. 2000;22:307-11.

50. Peek-Asa C, Zwerling C. Role of environmental interventions in injury control and prevention. Epidemiol Rev. 2003;25:77-89.

51. Jones SJ, Lyons RA, John A, et al. Traffic calming policy can reduce inequalities in child pedestrian injuries: database study. Inj Prev. 2005;11:152-56.

52. Laflamme L. Explaining socio-economic differences in injury risks. Inj Control Saf Promot. 2001;8:149-53.

53. Hamel D, Pampalon R. Trauma and deprivation in Quebec. Québec: Institut national de santé publique du Québec, 2002. 8 p. 